\title{
NORM BASIS FOR CONTROL AND OPTIMIZATION OF PHYSICAL DEVELOPMENT AND SPECIFIC WORKABILITY OF 11-12-YEAR-OLD CYCLISTS
}

\author{
Iv. Kolev* \\ Department „Technical and Ice Sports“, Coaches Faculty, National Sports Academy „Vassil Levski“, \\ Sofia, Bulgaria
}

\begin{abstract}
The development of norms base is one of the most important conditions for optimization of sport straining process. While the factor weights allow optimization of the training process in a strategic aspect (depending on the importance of the individual performance indexes), the evaluation of the results through normative tables allows for tactical (current) optimization of the training, depending on the current level of preparedness. The aim of the following study is to optimize the training process of 11-12-year-old cyclists by development of norms base for control of physical development and cyclists' specific workability. Conclusion. Statistical verification of the reliability and reproducibility of the indexes include in the test battery was made. The most informative indexes for selection and sports orientation in cycling in the age group 11-12-years have been identified. Assessing the level of observed signs allows to identify the strengths of future training with each young cyclist.
\end{abstract}

Key words: cycling, adolescents, study.

\section{INTRODUCTION}

It is known (1) that the cumulative effect of the training load is characterized by the accumulation of "traces, reflections" in the body of the athlete, leading to lasting, persistent, characteristics of the general and specific workability.

The effort to gather wider, richer and more objective information on the level of sport preparedness leads to the search for and use of highly effective ways and means of registration of specific workability individual parameters and specific working capacity. Any omission in the information flow reduces the effectiveness of the overall control analysis and management of sport training process (2, $3)$.

The development of norms base is one of the most important conditions for optimization of

\footnotetext{
*Correspondence to: Ivan Kolev, National Sports Academy ,,Vassil Levski“", Coaches Faculty, Department „,Technical and Ice Sports “, Studentski grad, Acad. Stefan Mladenov 21 str., 1700 Sofia, Bulgaria,kolevnsa@abv.bg
}

sport straining process. While the factor weights allow optimization of the training process in a strategic aspect (depending on the importance of the individual performance indexes), the evaluation of the results through normative tables allows for tactical (current) optimization of the training, depending on the current level of preparedness (4).

The aim of the following study is to optimize the training process of 11-12-year-old cyclists by development of norms base for control of physical development and cyclists' specific workability.

\section{METHODS}

Subject of the study is the system for sport selection and orientation, as well as the initial training of young cyclists in the age 11-12years.

Object of the study is the physical development physical training and both technical and tactical skills of young cyclists from the Republic of Bulgaria. 
Respondents of the study are 20 boys training cycling in cycling clubs in Bulgaria.

In order to solve the aim and purpose of the study we applied the following research methods: methodical literature overview, anthropometry, sport-pedagogical testing.

The test included in the study reveal physical development, sport training and help the assessment of the young cyclists' development. The set of tests includes 15 indexes revealing information about respondents anthropometric and motor abilities, which are divided into the following characteristic groups:

- Physical development assessment - 3 indexes (including additionally calculated Body Mass Index);

- Physical fitness - 7 indexes;

- For specific technical training - 5 indexes.

Collected information was processed using appropriate mathematical and statistical methods: variance analysis, evaluation using sigmal method, index method.

\section{RESULTS EVALUATION}

For the purpose of the study we analyze the average values and variability of research indexes. On this basis a normative table was developed, which allows easy and quick assessment of each sign, giving information about physical, specific sport and technical training aspects of cyclists from the studied age group (11-12-years).

The applied evaluation system makes possible to compare the results of differently dimensioned tests and indexes (measured in $\mathrm{m}$, $\mathrm{cm}$, sec. or $\mathrm{kg}$ ).

As an example, here we show only a part of the normative evaluation table, in which are presented only five of the analyzed indexes (Table 1).

The applied 50-point scoring system allows accurate counting of the training indexes improvement even in shorter periods of time, which in turns allows on time adjustment of training means and loads.

The average survey level corresponds to 25 points. If performance is better than average the score will be above 25 points and vice versa - for worse results, the marks are lower than 25 points.

For achieving effective control over the physical and sport-technical training of cyclists (from studied age group), a number of activities need to be carried out, following the sequence:

1. To apply the entire set of tests, as follows:

- Initially - in the first two training sessions of the respective sportcompetitive year;

- Interim - at the end of December;

- Excessively - in the last two training session for the season.

2. For the implementation of the operative control, other intermediate tests may be conducted only on part of the test, determined by the head coach.

3. All operations regarding results registration and their evaluation are done by the coach or his assistant (possibly cycling specialist).

4. The obtained data from the test shall be recorded in specially developed forms and stored in the sport club archives for the purpose of long-term follow-up of the results from the training progress with adolescent cyclists.

5. When working with the normative tables, you need to know the following:

- The column numbers correspond to the index number;

- The evaluation of a results is done by finding the relevant index in the corresponding table and the result compared with the values indicated in the column. Against this horizontal value in the first column ("Points"), the score gives to the respondent points valid for the relevant index.

- If the evaluated result falls between two values, it equals to the weaker results (by quality) value;

- In the cases where $T=25$ points, the evaluated result corresponds to the average level of development of given attribute for the respective age group;

- In cases where the score is beyond the limit of the scoring table (from 1 to 50 points), it is score with 51 points if it is higher in quality, and with 0 points if it is lower in quality. 
KOLEVIV.

Table 1. Normative evaluation table for physical development and specific performance assessment of 11-12 year-old cyclists (sample)

\begin{tabular}{|c|c|c|c|c|c|}
\hline \multirow[b]{3}{*}{ points } & $\underline{1}$ & $\underline{2}$ & $\underline{\mathbf{3}}$ & $\underline{4}$ & $\underline{5}$ \\
\hline & $\mathbf{3 0} \mathbf{~ m}$ & $30 \mathrm{~m}$ & $100 \mathrm{~m}$ & $200 \mathrm{~m}$ & $500 \mathrm{~m}$ \\
\hline & $\begin{array}{l}\text { crouch } \\
\text { start }\end{array}$ & $\begin{array}{l}\text { standing } \\
\text { start }\end{array}$ & $\begin{array}{l}\text { flying } \\
\text { start }\end{array}$ & $\begin{array}{l}\text { flying } \\
\text { start }\end{array}$ & $\begin{array}{l}\text { start } \\
\text { from } \\
\text { place }\end{array}$ \\
\hline 50 & \begin{tabular}{|l|}
4,94 \\
\end{tabular} & 4,05 & 6,46 & 12,74 & 36,34 \\
\hline 49 & 4,95 & 4,06 & 6,51 & 12,80 & 36,59 \\
\hline 48 & 4,96 & 4,07 & 6,55 & 12,86 & 36,84 \\
\hline 47 & 4,97 & 4,08 & 6,60 & 12,92 & 37,09 \\
\hline 46 & \begin{tabular}{|l|}
4,98 \\
\end{tabular} & 4,09 & 6,64 & 12,98 & 37,34 \\
\hline 45 & 5,00 & 4,10 & 6,69 & 13,04 & 37,59 \\
\hline 44 & 5,01 & 4,11 & 6,73 & 13,10 & 37,84 \\
\hline 43 & 5,02 & 4,12 & 6,78 & 13,17 & 38,09 \\
\hline 42 & 5,03 & 4,13 & 6,82 & 13,24 & 38,34 \\
\hline 41 & 5,04 & 4,14 & 6,87 & 13,31 & 38,59 \\
\hline 40 & 5,05 & 4,15 & 6,91 & 13,38 & 38,84 \\
\hline 39 & 5,06 & 4,16 & 6,96 & 13,45 & 39,09 \\
\hline 38 & 5,07 & 4,17 & 7,01 & 13,55 & 39,35 \\
\hline 37 & 5,09 & 4,18 & 7,06 & 13,65 & 39,61 \\
\hline 36 & 5,10 & 4,19 & 7,11 & 13,75 & 39,87 \\
\hline 35 & 5,11 & 4,20 & 7,16 & 13,85 & 40,13 \\
\hline 34 & 5,12 & 4,21 & 7,21 & 13,95 & 40,39 \\
\hline 33 & 5,13 & 4,22 & 7,26 & 14,07 & 40,66 \\
\hline 32 & 5,14 & 4,23 & 7,32 & 14,18 & 40,93 \\
\hline 31 & 5,15 & 4,24 & 7,37 & 14,29 & 41,20 \\
\hline 30 & 5,16 & 4,25 & 7,43 & 14,40 & 41,47 \\
\hline 29 & 5,18 & 4,26 & 7,48 & 14,51 & 41,74 \\
\hline 28 & \begin{tabular}{|l|}
5,19 \\
\end{tabular} & 4,27 & 7,54 & 14,62 & 42,01 \\
\hline 27 & 5,20 & 4,28 & 7,59 & 14,74 & 42,28 \\
\hline 26 & 5,21 & 4,29 & 7,65 & 14,85 & 42,55 \\
\hline 25 & 5,22 & 4,30 & $\mathbf{7 , 7 0}$ & 14,96 & 42,82 \\
\hline 24 & 5,24 & 4,33 & 7,75 & 15,07 & 43,08 \\
\hline 23 & 5,26 & 4,36 & 7,80 & 15,18 & 43,34 \\
\hline 22 & 5,28 & 4,40 & 7,85 & 15,29 & 43,60 \\
\hline 21 & 5,30 & 4,43 & 7,90 & 15,40 & 43,86 \\
\hline 20 & 5,32 & 4,46 & 7,95 & 15,51 & 44,12 \\
\hline 19 & 5,34 & 4,49 & 8,00 & 15,62 & 44,38 \\
\hline 18 & \begin{tabular}{|l}
5,35 \\
\end{tabular} & 4,52 & 8,05 & 15,73 & 44,64 \\
\hline 17 & 5,37 & 4,56 & 8,10 & 15,84 & 44,90 \\
\hline 16 & 5,39 & 4,59 & 8,15 & 15,95 & 45,16 \\
\hline 15 & 5,41 & 4,62 & 8,20 & 16,05 & 45,41 \\
\hline 14 & 5,43 & 4,65 & 8,24 & 16,15 & 45,66 \\
\hline 13 & 5,45 & 4,68 & 8,29 & 16,25 & 45,91 \\
\hline 12 & \begin{tabular}{|l|}
5,47 \\
\end{tabular} & 4,72 & 8,33 & 16,35 & 46,16 \\
\hline 11 & 5,49 & 4,75 & 8,38 & 16,45 & 46,41 \\
\hline 10 & \begin{tabular}{|l|}
5,51 \\
\end{tabular} & 4,78 & 8,42 & 16,51 & 46,65 \\
\hline 9 & \begin{tabular}{|l|}
5,53 \\
\end{tabular} & 4,81 & 8,47 & 16,57 & 46,89 \\
\hline 8 & \begin{tabular}{|l|}
5,55 \\
\end{tabular} & 4,84 & 8,51 & 16,63 & 47,13 \\
\hline 7 & 5,57 & 4,88 & 8,56 & 16,69 & 47,37 \\
\hline 6 & \begin{tabular}{|l}
5,58 \\
\end{tabular} & 4,91 & 8,60 & 16,75 & 47,61 \\
\hline 5 & \begin{tabular}{|l|}
, 600 \\
\end{tabular} & 4,94 & 8,65 & 16,81 & 47,85 \\
\hline 4 & \begin{tabular}{|l|}
5,62 \\
\end{tabular} & 4,97 & 8,69 & 16,87 & 48,09 \\
\hline 3 & \begin{tabular}{|l|}
5,64 \\
\end{tabular} & 5,00 & 8,74 & 16,93 & 48,33 \\
\hline 2 & \begin{tabular}{|l|}
5,66 \\
\end{tabular} & 5,04 & 8,78 & 16,99 & 48,57 \\
\hline 1 & 5,68 & 5,07 & 8,83 & 17,05 & 48,81 \\
\hline
\end{tabular}




\section{TRAINING OPTIMIZATION}

According to the sport science theory (1) the adaptation process is a non-linear function of the physical loads - the dependence "doseeffect" dependence is evolving through the socalled logistic curve. This means that, depending on the current state of the sign for which the relevant indexes carry information, a similar training load will have a different effect. The higher the level of development, that is, the better the achievement, the lesser the increase that can be expected in a unit of workout. This gives us a reason to believe that during training process it is more appropriate to focus on improving the performance of those indexes that are lower at the time of the preparation - the estimates of $\mathrm{T}$-scores using the normative tables are lower.

Applying the T-scores assessment, as a private criterion for training optimization (5), allows to identify the highlights of the future training process of young cyclists' part of the study. The logic of using sigmal scores requires the efforts of both cyclists and coaches to be directed to raising the level of those signs that each of the respondents has the lowest score. It is clear that in order to achieve positive result in the future, it is extremely important to take care of the individual training work with each of the respondents. It is also necessary for the coaches to realize that efforts aimed at developing the signs in which the assessments are high will not have the same effect on the specific working capacity of young cyclists.

To support the process of optimization of selection and preparation, individual models of physical development and specific workability of respondents have been developed. The detailed analysis of these optimization models allows to reveal the characteristics of the physical development and specific working capacity of each of the competitors from the studied population.

Figure $\mathbf{1}$ is an example for individual optimization model of the physical development and the specific work capacity of one of the respondents from studied group - O. Tatar.

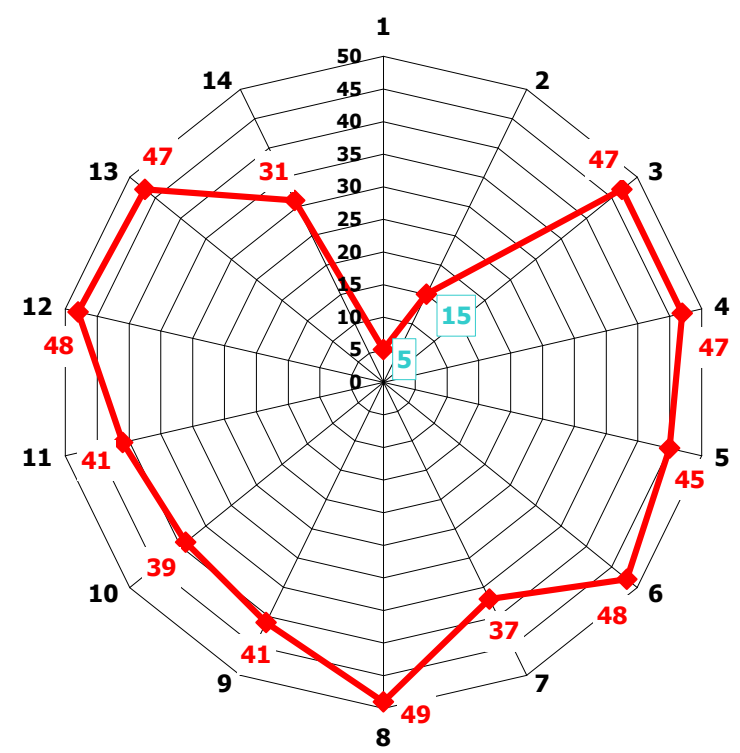

Figure 1. Physical development and specific workability individual optimization model of $\mathrm{O}$. Tatar (11-12-year-old)

The analysis of the model reveals that $\mathrm{O}$. Tatar has a very high level of development of almost all examined indexes. This confirmed by the sigmal scoring values (T-scores), which in 11 of all indexes are between 37 and 48 points.

However, as can be seen from the figure, the score of this young cyclist on the $1^{\text {st }}$ and the $2^{\text {nd }}$ indexes are very low (respectively 5 and 15 points). This gives reason, with a high level of guarantee probability $(\mathrm{Pt} \geq 95 \%)$ to claim that O. Tatar has a low level of development of his speed capabilities. Consequently, in the future, the emphasis during training process with this cyclist should be focused primarily on sprint capabilities development. Efforts to raise the level of other test points will not have the same training effect and will not lead to a significant increase in the level of their specific working capacity. 


\section{CONCLUSION AND}

\section{RECOMMENDATIONS}

1. Statistical verification of the reliability and reproducibility of the indexes include in the test battery was made.

2. The most informative indexes for selection and sports orientation in cycling in the age group 11-12-years have been identified.

3. A legal basis for assessment of physical development and specific working capacity of young 11-12-year-old cyclists has been developed.

4. Assessing the level of observed signs allows to identify the strengths of future training with each young cyclist.

5. Developed individual models allows optimization of the selection process and sport orientation in cycling.

\section{REFERENCES}

1. Jelyazkov, Tz., D. Dasheva. Fundamentals of sports training. In Bulgaria. "B - ins". Sofia. 2017.

2. Brogli, Y. Introduction to the theory and practice of controlling factors of sports achievement. In Bulgarian. Sofia.2012.

3. Carova, R. Problems of control in basketball. In Bulgarian. "B - ins". Sofia. 2013.

4. Jelyazkov, Tz. Methodological foundations of management and optimisation of the sports training for highly skilled athletes. Dees. work, Sofia, 1978.

5. Gyosheva, K., Carov, K., Carova, R. Basketball-control system evaluation and optimization of the sports training (girls and boys - 13-15 years). In Bulgaria. NSA. Sofia. 1990.

6. Milanova, P. Study of physical fitness in 14-15 old students, Sp. i N. br. 1, Sofia, 2013.

7. Kolev, I. Fundamentals of selection and orientation in cycling. In of Bulgarian. , NSA, Sofia. 2016.

8. Kolev, I. Fundamentals of selection and orientation in cycling. In of Bulgarian. Dees. work . NSA, Sofia, 2016.

9. Kolev, I. System for selection of sports cyclists. NSA Press, Sofia, 2012. 